\title{
Article \\ Strahler Ordering Analyses on Branching Coral Canopies: Stylophora pistillata as a Case Study
}

\author{
Yaniv Shmuel ${ }^{1,2,3, *}$, Yaron Ziv ${ }^{4}$ and Baruch Rinkevich ${ }^{2}$ (D) \\ 1 Marine Biology and Biotechnology Program, Department of Life Sciences, Ben-Gurion University of the \\ Negev, Eilat Campus, Beer-Sheva 8855630, Israel \\ 2 Israel Oceanography and Limnological Research, National Institute of Oceanography, Tel-Shikmona, \\ P.O. Box 9753, Haifa 3109701, Israel; buki@ocean.org.il \\ 3 The Interuniversity Institute for Marine Science, Eilat 88000, Israel \\ 4 Spatial Ecology Lab, Department of Life Sciences, Ben Gurion University of the Negev, \\ Beer-Sheva 8410501, Israel; yziv@bgu.ac.il \\ * Correspondence: yanivshm@post.bgu.ac.il
}

check for updates

Citation: Shmuel, Y.; Ziv, Y.; Rinkevich, B. Strahler Ordering Analyses on Branching Coral Canopies: Stylophora pistillata as a Case Study. J. Mar. Sci. Eng. 2022, 10, 121. https://doi.org/10.3390/ jmse10010121

Academic Editor: Carlo Cerrano

Received: 31 October 2021

Accepted: 13 January 2022

Published: 17 January 2022

Publisher's Note: MDPI stays neutral with regard to jurisdictional claims in published maps and institutional affiliations.

Copyright: (C) 2022 by the authors. Licensee MDPI, Basel, Switzerland. This article is an open access article distributed under the terms and conditions of the Creative Commons Attribution (CC BY) license (https:// creativecommons.org/licenses/by/ $4.0 /)$.

\begin{abstract}
The three-dimensional structural complexities generated by living sessile organisms, such as trees and branching corals, embrace distinct communities of dwelling organisms, many of which are adapted to specific niches within the structure. Thus, characterizing the build-up rules and the canopy compartments may clarify small-scale biodiversity patterns and rules for canopy constituents. While biodiversity within tree canopies is usually typified by the vertical axis that is delineated by its main compartments (understory, trunk, crown), traditional studies of coral canopy dwelling species are evaluated only by viewing the whole coral head as a single homogeneous geometric structure. Here, we employ the Strahler number of a mathematical tree for the numerical measurements of the coral's canopy complexity. We use the branching Indo-Pacific coral species Stylophora pistillata as a model case, revealing five compartments in the whole coral canopy volume (Understory, Base, Middle, Up, and Bifurcation nods). Then, the coral's dwellers' diel distribution patterns were quantified and analyzed. We observed 114 natal colonies, containing 32 dwelling species (11 sessile), totaling 1019 individuals during day observations, and 1359 at night (1-41 individuals/colony). Biodiversity and abundance associated with Strahler numbers, diel richness, abundance, and patterns for compartmental distributions differed significantly between day/night. These results demonstrate that the coral-canopy Strahler number is an applicable new tool for assessing canopy landscapes and canopy associated species biodiversity, including the canopy-compartmental utilization by mobile organisms during day/night and young/adult behaviors.
\end{abstract}

Keywords: Strahler order; marine forest animals; structure complexity; Eilat; coral reef; canopy; coral dwellers; day/night observations

\section{Introduction}

Coral reefs and tropical forests, two of the most biodiverse ecosystems on earth [1-4], rely on the three-dimensional (3D) structural complexity generated by their operational building units, the corals and trees, respectively [5-7]. The discrete landscapes developed by these sessile organisms construct heterogeneous habitats that enhance productivity and biodiversity $[6,8,9]$.

Branching organisms are the key building units in forests and coral reefs. Corals exhibit taxon-specific canopy structures and are crowned by morphometric modifications within their canopies, habitats that are under the control of biological and environmental drivers [10-12]. In trees, the canopies create a wide diversity of habitats that are enclosed within one of three major organismal compartments, the crown, trunk, and understory [6,13]. These categorizations that considers functional properties of the tree's 3D structures could be harnessed for the study of the enclosed spaces within branching 
coral canopies. The spaces within coral canopies create ecological niches to obligate and facultative inhabiting biota $[14,15]$ that provide supporting services, including shelter, food supply, improved foraging, mediation of hydrodynamic stressors, and more [7,16]. An additional vital ecological service is that the overall 3D structure generated by an individual tree or a coral colony (termed here as a canopy) harbors a distinct community of organisms at any dynamic space and time dimension $[17,18]$.

Stylophora pistillata (family Pocilloporidae) is a widely distributed branching coral species in the northern Gulf of Eilat, Red Sea (Figure 1a). The colonial architectures in this species is established through iterated processes of polyps and branches [10], forming shrublike shapes. Along astogeny, up-growing branches are primarily added by dichotomous bifurcation at the branch-tips that usually form unequally-sized axes. Upgrowing branches further bud side growing branches that add to the 3D complexity [19]. The resulting structure of $S$. pistillata canopies approximate spheres, branded with a wide range of intra-canopy spaces that develop during coral astogeny, between the structural mesh of up-growing and side-growing branches [19] that may be modified over the life span of a colony [20].
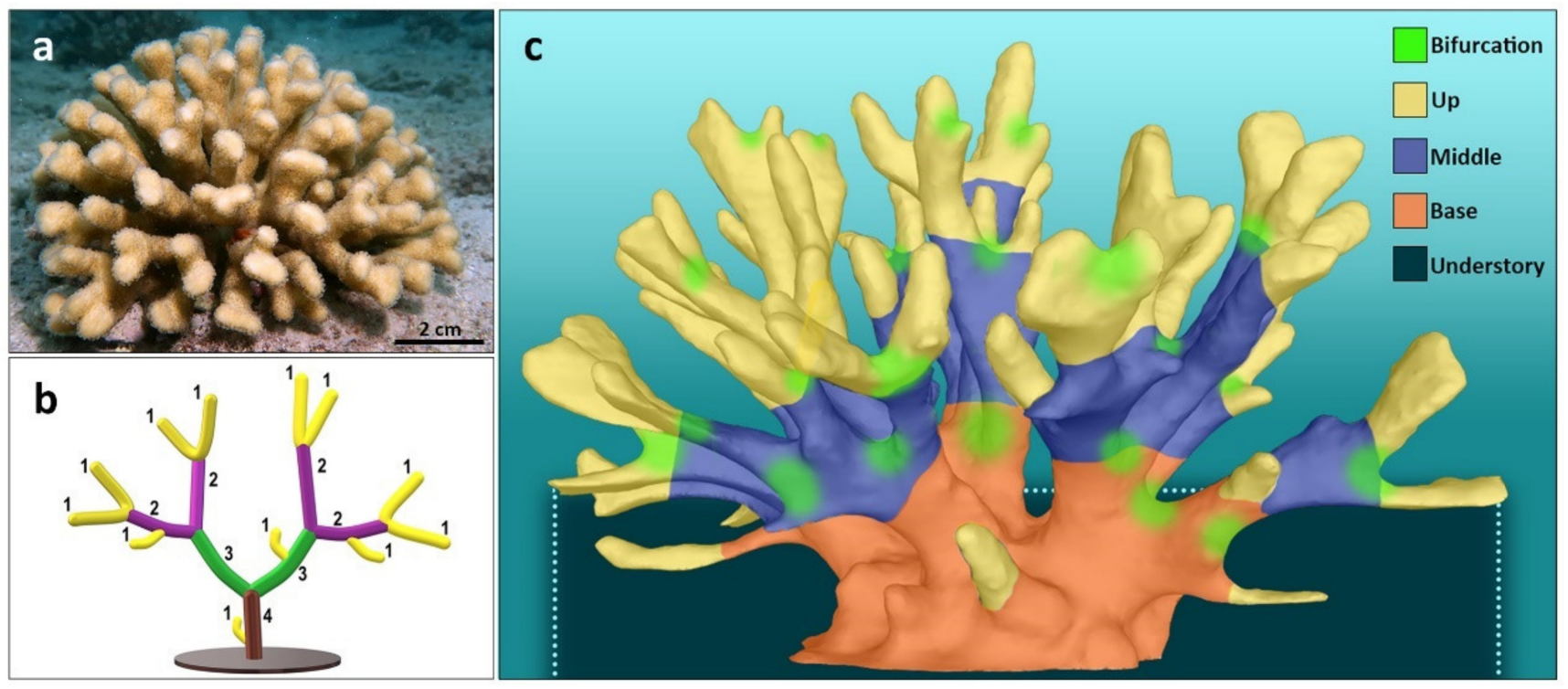

Figure 1. (a) A colony of Stylophora pistillata from Eilat's reef (4 m depth); (b) A schematic illustration for Strahler order system applying on a coral canopy. Initiate branches receive the first order $(1$, yellow branches), and branches that are formed by joining of two branches of the same order $\mathrm{i}$, receive the order i +1 ; (c) Stylophora pistillata canopy compartments as revealed via the use of branch analyses through the Strahler order technique: Up: the outermost canopy layer, in analogy to the foliage of the tree canopy. This is the canopy peripheral volume that encloses the first Strahler order branches; Base: the canopy two highest Strahler numbers of a specific coral colony, that in analogical to trees create the canopy's trunk; Middle: middle branches area, this is the space above the base and below the first Strahler branches, resembling the crown area of the tree's canopy.; Understory: the space found beneath the canopy base that occupies the space between the coral's substate plain to the parallel first canopy branches. Bifurcation: the branches node, these are the spaces surrounding the initiating axes of all branches above the base. Yellow = 'up' compartment; Purple = 'middle'; Red = 'base'; Green = 'bifurcation'; Dark-blue = 'understory'. Part c was extracted from a S. pistillata skeleton using Autodesk ReCap Photo and Photoshop programs. 
Despite the contribution of canopy structures to coral dwellers' life history traits [21-23], the literature focuses on the identification of the dwellers' biodiversity vs. general coral parameters, such as the consideration of the entire volume as a single space, total numbers of species, individuals, etc. [24-28]. Few studies address the influence of the canopy structure attributes on dwelling biota. Yet, these studies compare morphological complexities such as the interbranch space between different coral species, or between coral populations of a single taxon exposed to various environmental conditions [15,18,26,29-31], without considering the potential contribution of the niches created along the vertical axis. Further, as many of the coral dwelling species are cryptic, observations are restricted to laboratory examinations, to biota examination via the coral host fragmentation, or to extensive field surveys on model species. The latter of these methodologies offers a broader ecological context and yet through a non-destructive routine [18,32].

Structure complexity for branching networks within a coral canopy can be depicted mathematically by hierarchical systems. One of which is the Strahler order, a numerical measure of branching complexity which was originally introduced in hydrology for defining river stream based on a hierarchy of tributaries [33]. In this system, ordering initiates at the terminal branches of the branch complex and increases when two branches of equal order meet (Figure 1b). While ordering techniques have already been applied decades ago for modeling the structure of terrestrial plants [34-37], and marine organisms such as bryozoans [38], sponges [39], and corals [11], this approach has not yet been introduced as a measurement for coral canopy complexity, and primarily for addressing canopy-associated species.

Working on the branching coral S. pistillata, we applied here the Strahler order as an analyzing tool of the coral canopy structure, to measure the consideration of its significance of the dweller communities. In particular, we tested the notion that coral colonies with a higher Strahler number would present higher structural complexity and by doing so that produce a variety of niches, thus harboring higher biodiversity [40,41]. In addition, we characterize the major coral canopy compartments occupied by specific dweller organisms at day and night times.

\section{Materials and Methods}

\subsection{Studied Sites and Survey Procedures}

This study was carried out in three sites at the Japanese Gardens, a narrow and shallow (2-7m depth) fringing reef on the west shoreline of the Gulf of Eilat, Red Sea $\left(29^{\circ} 30^{\prime} \mathrm{N}\right.$, $34^{\circ} 56^{\prime} \mathrm{E}$ ), which includes three reef locations, the lagoon, the reef flat and a shallow forereef, going down to 7-m depth. Visual surveys on S. pistillata colonies (canopies volumes $1.33-18,496 \mathrm{~cm}^{3}$ ) were conducted in situ by SCUBA and snorkel diving between June and September 2020. In order to include all sites and to mark the canopies for day/night surveys, belt transects $(50 \times 2 \mathrm{~m})$ were placed perpendicular to the coast outline, from the lagoon to fore-reef (each belt containing $>10$ S. pistillata colonies; at least 14 canopies per reef location), totaling 114 canopies. Each canopy was surveyed twice, first during day hours (3:00-5:00 p.m.) for canopy dwelling species and coral attributes, and then, during nighttime (20:30-11:30 p.m.), only for the dwelling species.

\subsection{Canopy Compartments}

Canopies inclusiveness space was delineated by five distinct compartments following Strahler orders and by integrating the conceptual tree-canopy compartments (Figure 1c), as follows: (1) the outermost compartment (up), this is the canopy's peripheral enclosed space that includes the spaces beneath the canopy contour, all created by branches belonging to the first Strahler order, bordering by the lower plan of the second order branches. Side branches [19] of the first Strahler order were eliminated from consideration except for cases where they actively shaped the canopy contour; (2) Canopy 'base' (base), the coral's main trunk that protrudes from the coral basal plate. For coral canopies composed of Strahler numbers of 4 to 6, base compartments were signified as the canopy's volume enclosing the 
two highest Strahler order branches, up to the branches' bifurcation point. For canopies that are composed of Strahler numbers 2 and 3, 'base' compartments were defined only for the highest Strahler order; (3) 'Middle' compartment (middle), for coral canopies composed of Strahler numbers of 3 to 6 , this is the volume that includes all spaces confined above the canopy 'base' compartment and below the 'up' compartment. In smaller size canopies of younger coral colonies that are composed of Strahler number 2, the 'middle' compartment is defined by the space from the canopy base to the mid length of the first branch order; (4) 'Understory' (un), the volume enclosed between the canopy substrate and the first branches growing parallelly to the canopy substrate plan; (5) 'Bifurcation' nodes (BIF), these are the spaces surrounding the initiating bifurcation budding axes above the base.

\subsection{Canopies Dwelling Species}

S. pistillata's canopy-dwelling species assemblages (diversity and abundance) were recorded in-situ for each of the five assigned canopy compartments. Individual species traveled between compartments during the canopy survey and were recorded for all crossed compartments. In order to reduce artifacts resulting from disruptions made by the observer, mobile species locations within the canopy structures were made first from a distance of one meter from the coral colony and then by slow approach, using a flashlight for meticulous examination. All observations were made without any manipulation or hand contacts (permit restrictions). Canopy dwelling species identification was made to the lowest possible taxonomic level afforded by the morphological traits. Small and visually undetectable organisms, such as plankton or algae, were not documented. Taxa that were impossible to identify at the species/genus level were grouped to a higher taxon (the snails Drupella and Coralliophila to the family Muricidae; brittle stars to the genera Ophiactis and Ophiocoma; hermit crabs to the family Paguroidea; fan worms to the genera Sabellastarte and Spirobranchus; all Pteriidae and Didemnidae species to family level). All recorded species were defined as either sessile or mobile organisms, with the only exception being the gull crab Hapalocarcinus marsupialis defined here as a 'sessile' species, as female crabs span their entire lifetime enclosed within galls they create in the corals' branches. Rare species were assigned to cases in which only 1-2 specimens were documented in all observations. The populations of the three most common mobile dwelling species that allowed statistical analyses were divided into three body size clusters, for which the dwelled compartments were recorded (T. cymodoce carapace width large $>2 \mathrm{~cm}$, medium $1-2 \mathrm{~cm}$, and small $<1 \mathrm{~cm}$; T. digitalis carapace width large $>1.5 \mathrm{~cm}$, medium $1-1.5 \mathrm{~cm}$, and small $<1 \mathrm{~cm}$; for Paguroidea shell diameter big $>3 \mathrm{~cm}$, medium $3-1 \mathrm{~cm}$, small $<1 \mathrm{~cm}$ ). These species body size was visually determined by their distinct morphometric size appearance.

\subsection{Canopies Attributes}

All canopies' attributes were recorded in situ. For each colony, depth and reef location (lagoon, reef flat, shallow fore-reef) were recorded, and colonial metrics, including canopy maximum perpendicular diameters (length, width), canopy height, and canopy base compartment height were measured by manual clipper $( \pm 0.1 \mathrm{~mm})$ after recording canopy dwellers statuses. Canopy volume was calculated as the half ellipsoid volume using the canopy's two perpendicular diameters and the coral height as the third axes. Canopies were further classified by their volume into three size groups (S-small, $<1200 \mathrm{~cm}^{3}$; M-medium, 1200 $>=<2800 \mathrm{~cm}^{3}$; L-large, $>2800 \mathrm{~cm}^{3}$ ). Strahler numbers were calculated for all branch pathways, starting from branch tips to canopy substrate, a process that took less than $30 \mathrm{~s}$; canopy Strahler number was determined as the highest ordering lane. Underwater photos for each colony were taken to validate dubious results and emerged queries (Canon G7X, Japan, and Nikon Coolpix W300, Japan). 


\subsection{Statistical Analyses}

Fisher alpha was calculated for day and night canopy biodiversity results. Similar to many other diversity indices, Fisher alpha is sensitive to communities with a low number of individuals, thus we dropped these canopies (total 24 colonies omitted). A paired permutation $t$-test was employed for finding significant differences between day vs. night in the communities' Fisher alpha, richness, and abundance ( $R$ packages: [42,43]). Prior to the richness and abundance analysis, extreme values (above quartile $Q 3+3 x$ interquartile range or below Q1-3 x interquartile range; the interquartile range was defined as Q3-Q1) were also omitted (1-4 colonies).

The contribution of canopy volume to the canopy's dwelling species richness and abundance was verified by linear regression with log-log transformation. Linear regression analyses were also used to determine the effect of canopy Strahler numbers as a numerical driver on dwelling species richness and abundance after log transformation. In addition, we investigate if the richness and abundance of the canopy's dwelling species is different between the Strahler number groups (categorical factor) with permutation ANOVA using distance matrices with post-hoc pairwise permutation and false discovery rate correction (R packages: $[44,45])$. Linear regression was performed on the correlation between canopy volumes and canopy Strahler numbers with a log volume transformation.

Community structures of canopy dwelling species between canopy's size groups and between the canopy's Strahler numbers for day and night observations were visualized by nonmetric multidimensional scaling (NMDS) ordination plot based on Bray-Curtis dissimilarities matrix with 0.85 power transformation on species abundance data. Differences between dwelling community groups were analyzed by distance-based PERMANOVA following a multivariate homogeneity of group dispersions. Posterior pairwise comparisons between groups were made by permutation MANOVA with a Holm-Bonferroni correction.

In order to estimate differences within population assemblage, between dwelling species body sizes and between day and night in relation to canopy compartments occupation, we performed Two-way PERMANOVA and Pairwise permutation MANOVA analyses based on Bray-Curtis dissimilarities matrix with 1.7 power transformation for each of the three most common mobile dweller species abundance data (R packages: $[42,43,46,47])$. Diagrammatic representation for other prevalent sessile and mobile species $(3 / 11$, and $9 / 21$, respectively) distributions along canopy compartments were visualized by bar plots. All analyses and plots performed using RStudio version 1.3.1093. program and Office software.

\section{Results}

\subsection{General}

A total of 32 species were identified dwelling in the 114 S. pistillata canopies surveyed at the Japanese Gardens site, eight of them were considered to be rare (Supplementary Table S1). Four taxa were identified to the family level, five to the genus, and 23 to the species name (Table 1). Eleven species (34.4\%) were identified as sessile species and their total individual count was 618. Mobile species total individuals count was 401 at day time surveys, and 741 during night time (Table 1). Per-canopy dwelling species, numbers ranged from 1 to 41 individuals. Canopy dwelling species assemblages were numerically dominated by the sessile bivalve Leiosolenus lessepsianus, recorded from 95 canopies and reaching up to $90 \%$ abundancy of total sessile species. Trapezia cymodoce was the most dominant species among the mobile species, recorded on 104 canopies with $39 \%$ and $20 \%$ of total mobile species abundancy at day and night observations (Figure 2). 


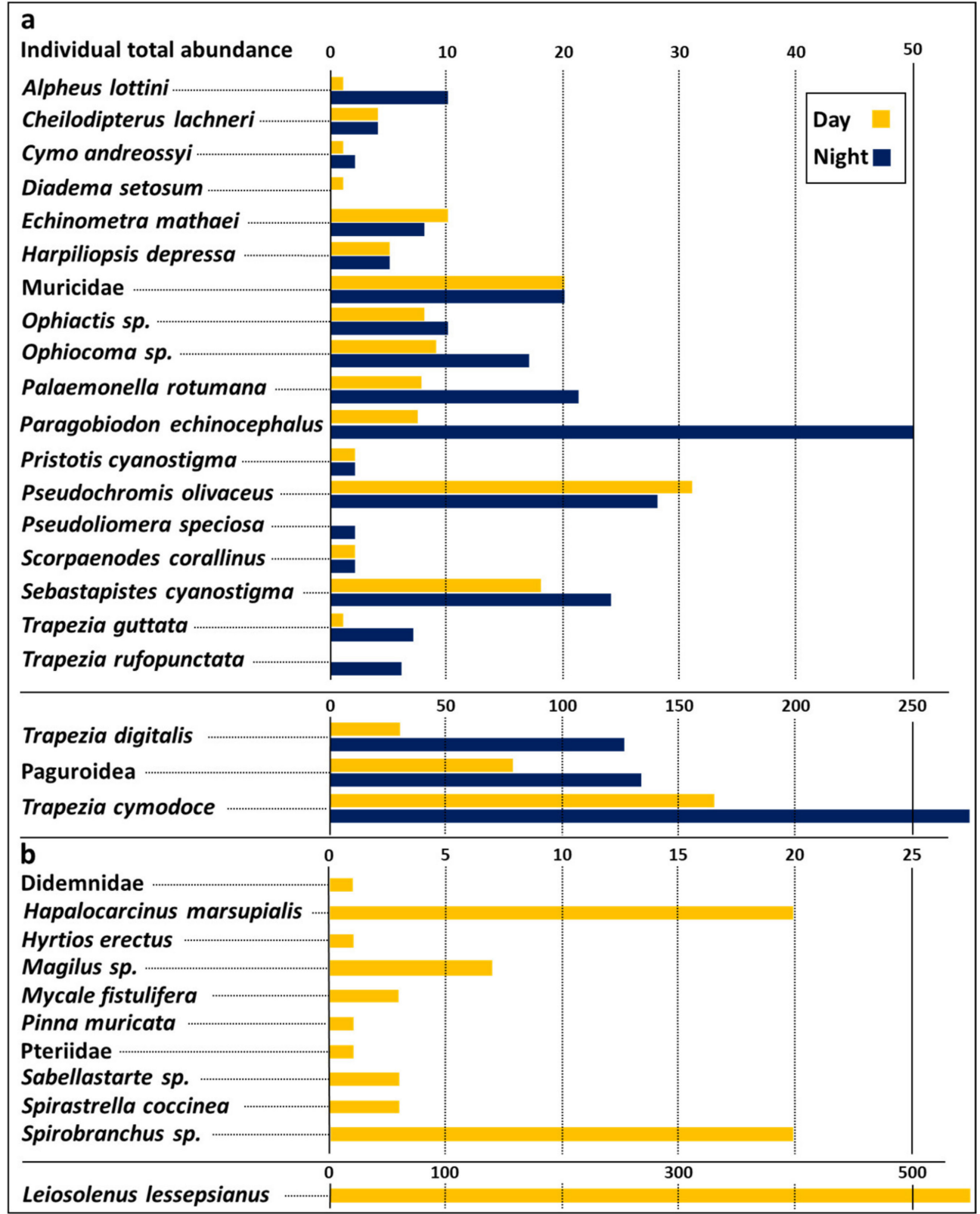

Figure 2. Canopy dweller species and total abundance within Stylophora pistillata canopies $(n=114)$ at day and night paired surveys. (a) mobile species, day time (orange) surveys, compared to night (blue); (b) sessile species counted in day surveys.

Except for the two canopy-nocturnal crustacean species Pseudoliomera speciosa and Trapezia rufopunctata, and the canopy-diurnal sea urchin Diadema setosum, all other mobile canopy dwelling species exhibited different day/night abundance distribution patterns, and mean richness and abundance were higher at night compared to day hours $(3.24 \pm 1.8$, $9 \pm 6$ for day and $4.23 \pm 2.1,11.9 \pm 8.2$ for night, richness and abundance, respectively; paired permutation $t$-test $p=0.002$ for either), further reflected by a significantly different Fisher alpha values $2.15 \pm 1.18$ day, and $2.84 \pm 1.34$ night; $p=0.0002$; Supplementary Table S2). 
Table 1. Total abundance of Stylophora pistillata dwelling species recorded for sessile species and for mobile species at day and night paired surveys $(n=114)$ as per the canopy volume size (S: small; M: medium; L: large) and the canopy's Strahler number (2-6), backslash indicate day/night abundance; $\mathrm{O}=$ obligate symbiont; $\mathrm{F}$ = facultative symbiont; $\mathrm{M}=$ mobile; $\mathrm{S}=$ sessile.

\begin{tabular}{|c|c|c|c|c|c|c|c|c|c|c|}
\hline \multirow{2}{*}{ Taxonomic Status } & \multirow{2}{*}{$\mathbf{S} / \mathbf{M}$} & \multirow{2}{*}{ Group } & \multicolumn{3}{|c|}{ Canopy Size } & \multicolumn{5}{|c|}{ Canopy Strahler Number } \\
\hline & & & $\mathbf{S}$ & $\mathbf{M}$ & $\mathbf{L}$ & 2 & 3 & 4 & 5 & 6 \\
\hline Trapeziidae, Trapezia cymodoce & M & $\mathrm{O}$ & $79 / 143$ & $34 / 48$ & $52 / 83$ & $3 / 7$ & $18 / 40$ & $91 / 129$ & $40 / 73$ & $13 / 25$ \\
\hline Trapeziidae, Trapezia digitalis & M & $\mathrm{O}$ & $17 / 62$ & $6 / 14$ & $7 / 50$ & $0 / 0$ & $2 / 17$ & $21 / 60$ & $6 / 32$ & $1 / 17$ \\
\hline Trapeziidae, Trapezia guttata & M & $\mathrm{O}$ & $0 / 4$ & $0 / 2$ & $1 / 1$ & $0 / 1$ & $0 / 0$ & $1 / 4$ & $0 / 2$ & $0 / 0$ \\
\hline Trapeziidae, Trapezia rufopunctata & M & $\mathrm{O}$ & $0 / 1$ & $0 / 0$ & $0 / 5$ & $0 / 0$ & $0 / 0$ & $0 / 5$ & $0 / 1$ & $0 / 0$ \\
\hline Alpheoidea, Alpheus lottini & M & $\mathrm{O}$ & $0 / 4$ & $0 / 1$ & $1 / 5$ & $0 / 0$ & $0 / 0$ & $0 / 2$ & $0 / 5$ & $1 / 3$ \\
\hline Xanthidae, Cymo andreossyi & M & $\mathrm{F}$ & $0 / 0$ & $0 / 0$ & $1 / 2$ & $0 / 0$ & $0 / 0$ & $0 / 0$ & $1 / 1$ & $0 / 1$ \\
\hline Xanthidae, Pseudoliomera speciosa & M & $\mathrm{F}$ & $0 / 0$ & $0 / 1$ & $0 / 1$ & $0 / 0$ & $0 / 0$ & $0 / 2$ & $0 / 0$ & $0 / 0$ \\
\hline Paguroidea & M & $\mathrm{F}$ & $29 / 41$ & $13 / 18$ & $37 / 74$ & $1 / 4$ & $6 / 9$ & $27 / 40$ & $30 / 47$ & $15 / 33$ \\
\hline Palaemonidae, Harpiliopsis depressa & M & $\mathrm{F}$ & $5 / 5$ & $0 / 0$ & $0 / 0$ & $0 / 0$ & $0 / 0$ & $5 / 5$ & $0 / 0$ & $0 / 0$ \\
\hline Palaemonidae, Palaemonella rotumana & M & $\mathrm{F}$ & $1 / 9$ & $2 / 4$ & $4 / 8$ & $0 / 0$ & $0 / 3$ & $2 / 10$ & $1 / 3$ & $4 / 5$ \\
\hline Gobiidae, Paragobiodon echinocephalus & M & $\mathrm{F}$ & $5 / 21$ & $2 / 8$ & $0 / 11$ & $0 / 0$ & $0 / 4$ & $5 / 23$ & $2 / 11$ & $0 / 2$ \\
\hline Scorpaenidae, Scorpaenodes corallinus & M & $\mathrm{F}$ & $0 / 0$ & $0 / 0$ & $2 / 2$ & $0 / 0$ & $0 / 0$ & $0 / 0$ & $0 / 0$ & $2 / 2$ \\
\hline $\begin{array}{c}\text { Scorpaenidae, Sebastapistes } \\
\text { cyanostigma }\end{array}$ & M & $\mathrm{F}$ & $2 / 6$ & $1 / 3$ & $15 / 15$ & $0 / 0$ & $0 / 0$ & $9 / 15$ & $6 / 7$ & $3 / 2$ \\
\hline Apogonidae, Cheilodipterus lachneri & M & $\mathrm{F}$ & $0 / 0$ & $0 / 0$ & $4 / 4$ & $0 / 0$ & $0 / 0$ & $0 / 0$ & $0 / 0$ & $4 / 4$ \\
\hline $\begin{array}{c}\text { Pseudochromidae, Pseudochromis } \\
\text { olivaceus }\end{array}$ & M & $\mathrm{F}$ & $10 / 6$ & $9 / 6$ & $12 / 16$ & $0 / 0$ & $1 / 1$ & $17 / 9$ & $11 / 11$ & $3 / 7$ \\
\hline Diadematidae, Diadema setosum & M & $F$ & $0 / 0$ & $0 / 0$ & $1 / 0$ & $0 / 0$ & $0 / 0$ & $0 / 0$ & $1 / 0$ & $0 / 0$ \\
\hline Echinometridae, Echinometra mathaei & M & $\mathrm{F}$ & $\frac{1}{4}$ & $4 / 3$ & $5 / 1$ & $0 / 0$ & $0 / 1$ & $6 / 5$ & $0 / 2$ & $4 / 0$ \\
\hline Ophiactidae, Ophiactis sp. & M & $\mathrm{F}$ & $1 / 1$ & $1 / 5$ & $6 / 4$ & $0 / 0$ & $1 / 1$ & $6 / 6$ & $1 / 3$ & $0 / 0$ \\
\hline Ophiocomidae, Ophiocoma sp. & M & $\mathrm{F}$ & $2 / 7$ & $2 / 1$ & $5 / 9$ & $0 / 0$ & $1 / 1$ & $2 / 8$ & $3 / 6$ & $3 / 2$ \\
\hline Pomacentridae, Pristotis cyanostigma & M & $\mathrm{F}$ & $0 / 0$ & $0 / 0$ & $2 / 2$ & $0 / 0$ & $0 / 0$ & $0 / 0$ & $1 / 1$ & $1 / 1$ \\
\hline $\begin{array}{c}\text { Muricidae (Coralliophila } \\
\text { sp./Drupella sp.) }\end{array}$ & M & $\mathrm{O}$ & $7 / 7$ & $2 / 2$ & $11 / 11$ & $0 / 0$ & $1 / 1$ & $6 / 6$ & $4 / 4$ & $9 / 9$ \\
\hline $\begin{array}{c}\text { Cryptochiridae, Hapalocarcinus } \\
\text { marsupialis }\end{array}$ & $S$ & $\mathrm{O}$ & 16 & 1 & 3 & 1 & 2 & 11 & 6 & 0 \\
\hline Mytilidae, Leiosolenus lessepsianus & S & $\mathrm{O}$ & 292 & 107 & 159 & 8 & 94 & 265 & 145 & 46 \\
\hline Didemnidae & $S$ & $\mathrm{~F}$ & 0 & 0 & 1 & 0 & 0 & 0 & 1 & 0 \\
\hline Spirastrellidae, Spirastrella coccinea & $S$ & $\mathrm{~F}$ & 0 & 1 & 2 & 0 & 0 & 1 & 1 & 1 \\
\hline Thorectidae, Hyrtios erectus & $S$ & $\mathrm{~F}$ & 0 & 0 & 1 & 0 & 0 & 0 & 1 & 0 \\
\hline Mycalidae, Mycale fistulifera & S & $\mathrm{F}$ & 1 & 2 & 0 & 0 & 0 & 2 & 1 & 0 \\
\hline Muricidae, Magilus sp. & $S$ & $\mathrm{~F}$ & 5 & 1 & 1 & 4 & 1 & 2 & 0 & 0 \\
\hline Pinnidae, Pinna muricata & $S$ & $\mathrm{~F}$ & 0 & 0 & 1 & 0 & 0 & 0 & 1 & 0 \\
\hline Pteriidae & $\mathrm{S}$ & $\mathrm{F}$ & 0 & 0 & 1 & 0 & 0 & 1 & 0 & 0 \\
\hline Sabellidae, Sabellastarte sp. & S & $\mathrm{F}$ & 0 & 1 & 2 & 0 & 0 & 1 & 2 & 0 \\
\hline Serpulidae, Spirobranchus sp. & $S$ & $\mathrm{~F}$ & 10 & 5 & 5 & 0 & 2 & 9 & 3 & 6 \\
\hline
\end{tabular}

\subsection{Effect of Canopy Size and Canopy Strahler Number on Associated Communities}

Canopy dwelling species day/night richness and abundance values were correlated with canopy volumes and canopy Strahler numbers (Figure 3; Supplementary Table S3; linear regression analyses, $p=0.0001)$. The consideration of the canopy Strahler number as a categorical factor revealed that colonies with canopy Strahler numbers 5 and 6 were not significantly different from each other, while colonies with canopy Strahler number 2 were significantly different in all analyses (Figure 3; Supplementary Table S4; Permutation one-way ANOVA, $p=0.001$ ). Similar results were revealed for the relationship between canopy volumes and canopy Strahler numbers (linear regression R-square 0.61, F-180.8, DF $1-112, p<0.001)$. 

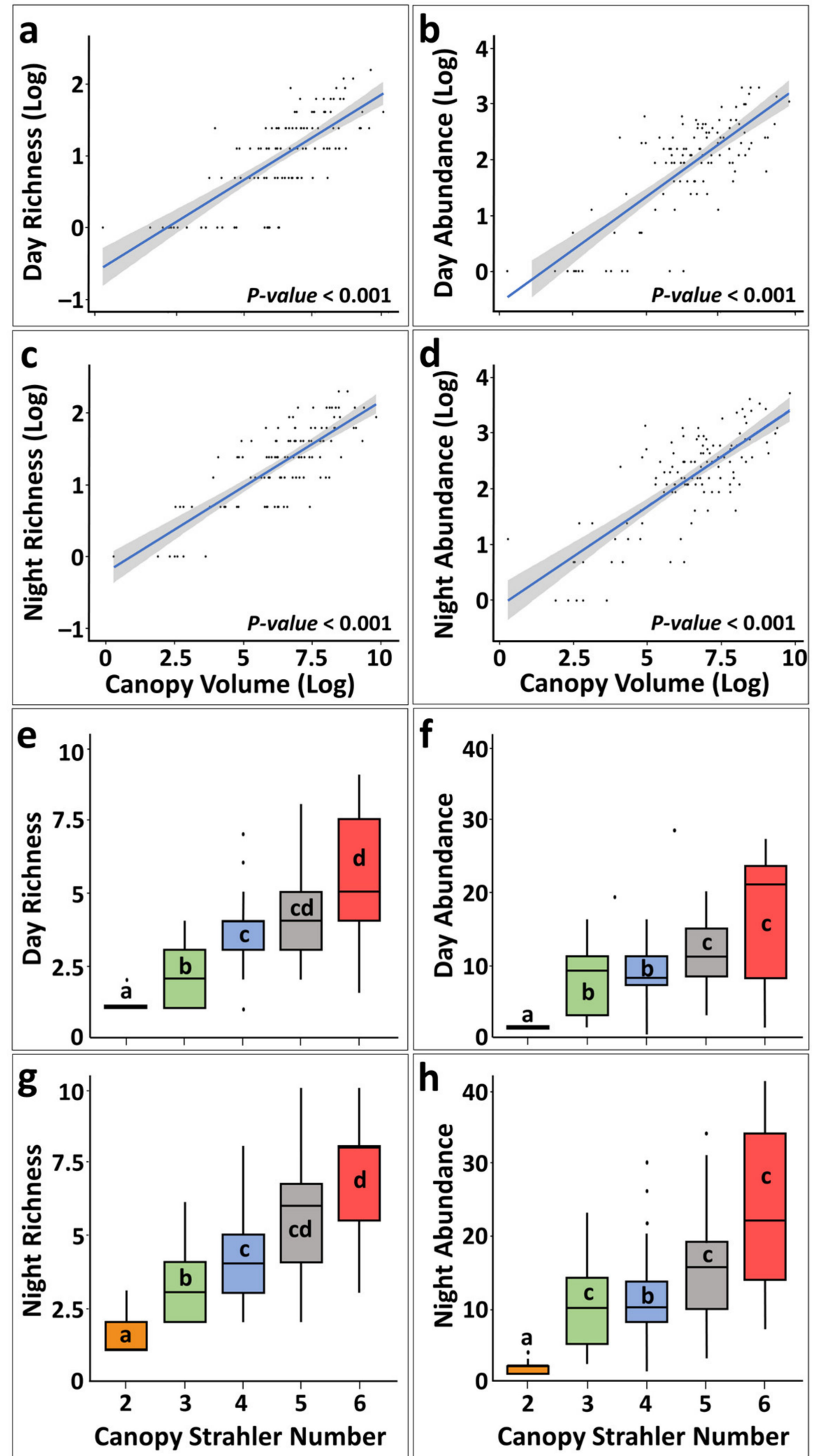

Figure 3. Correlation between canopy volume and canopy Straler number to day/night richness and abundance. (a-d) Linear regression of Log-Log canopy volume vs. richness/abundance. Shaded areas are the standart errors for the regressions; (e-h) Canopy Strahler number vs. richness/abundance, letters indicat significantly differet groups (Permutation one way ANOVA). 


\subsection{Species Compositions}

Total (inclusive day/night) mean of canopy dwelling species richness (number of species) for the three canopy size groups (, $\mathrm{M}$, and $\mathrm{L}$ ), calculated for day and night together, revealed twice as high richness in large colonies than in small colonies $(2.9 \pm 1.6[n=73]$, $4.32 \pm 1.37[n=19]$, and $5.91 \pm 2.01[n=22]$, respectively). Rare species $(n=8)$ were mostly found on larger canopies, with only one rare species, the flattened shrimp Harpiliopsis depressa recorded in a medium-sized canopy (Table 1). Similar results were recorded for richness vs. canopy Strahler number, with almost $5 \times$ higher richness in canopy Strahler number 6 as compared to canopy Strahler number $2(1.31 \pm 0.55(n=13), 2.74 \pm 1.21$ $(n=17), 3.86 \pm 1.56(n=55), 4.84 \pm 1.98(n=22)$, and $6.21 \pm 2.49(n=7)$, for canopy Strahler numbers 2 to 6 , respectively) and rare species were found on more structurally complex canopy Strahler number 4 and above (Table 1 ).

Nonmetric multidimensional scaling (NMDS) visualization for canopy dwelling species communities (Figure 4), vs. canopies size classes (large, medium, small) or canopy Strahler number (2-6), revealed an augmented similarity of these communities as canopy size or canopy Strahler number increase, in either day or night. Despite the limited ability of these analyses to explain the variation between the canopy sizes or between Strahler number groups ( $6 \%$ to $17 \%$, Table 2), all communities of the larger size canopies or the highest canopy Strahler number ordination are located at the NMDS center with a narrow dispersal, while communities of the smallest size canopies or those with the lowest canopy Strahler number, dispersed widely in the NMDS plane. Posteriori pairwise permutation MANOVA results for canopy sizes showed that during the day only the canopy dwelling species community residing in small canopies differed from medium and large size canopies, while at night, all three canopy group sizes were significantly different from each other. Similar outcomes were revealed for other canopy Strahler numbers. During the day, just the communities of canopy Strahler number 2 were significantly different from all other canopy Strahler number (SC 3-6), and during the night, communities of canopy Strahler numbers 2, 3 and 4 were different from canopy Strahler number 6 communities

Table 2. Summary of one-way PERMANOVA and pairwise permutation MANOVA results for differences between canopy dwelling communities, performed separately for each survey (day, night) on colony size (small, medium, large) or colony Strahler numbers (2-6), based on Bray-Curtis dissimilarity and a 0.85 power transformation of canopy dwelling species abundance data. Different letters indicate significant different group.

\begin{tabular}{|c|c|c|c|c|c|c|}
\hline \multicolumn{7}{|c|}{ Distance-Based PERMANOVA } \\
\hline & & df & MS & F. Model & $\mathrm{R} 2$ & $\mathrm{P}$ \\
\hline \multirow[t]{2}{*}{ Canopy size } & Day & 2 & 0.7079 & 3.5759 & 0.0605 & 0.002 \\
\hline & Residuals & 111 & 0.1979 & & 0.9394 & \\
\hline \multirow[t]{2}{*}{ Canopy size } & Night & 2 & 0.8267 & 4.7925 & 0.0795 & 0.001 \\
\hline & Residuals & 111 & 0.1725 & & 0.9205 & \\
\hline \multirow[t]{2}{*}{ Canopy Strahler No. } & Day & 4 & 0.7899 & 4.2563 & 0.1351 & 0.001 \\
\hline & Residuals & 109 & 0.1856 & & 0.8649 & \\
\hline \multirow[t]{2}{*}{ Canopy Strahler No. } & Night & 4 & 0.8967 & 5.678 & 0.1724 & 0.001 \\
\hline & Residuals & 109 & 0.1579 & & 0.8275 & \\
\hline \multicolumn{7}{|c|}{ Pairwise Permutation MANOVA } \\
\hline \multirow[t]{3}{*}{ Canopy size } & & Small & Medium & Large & & \\
\hline & Day & a & $\mathrm{b}$ & $b^{\circ}$ & & \\
\hline & Night & a & $\mathrm{b}$ & c & & \\
\hline \multirow[t]{3}{*}{ Canopy Strahler No. } & & 2 & 3 & 4 & 5 & 6 \\
\hline & Day & a & $b$ & $\mathrm{~b}$ & $\mathrm{~b}$ & $b$ \\
\hline & Night & a & $\mathrm{b}$ & $\mathrm{b}$ & bc & c \\
\hline
\end{tabular}



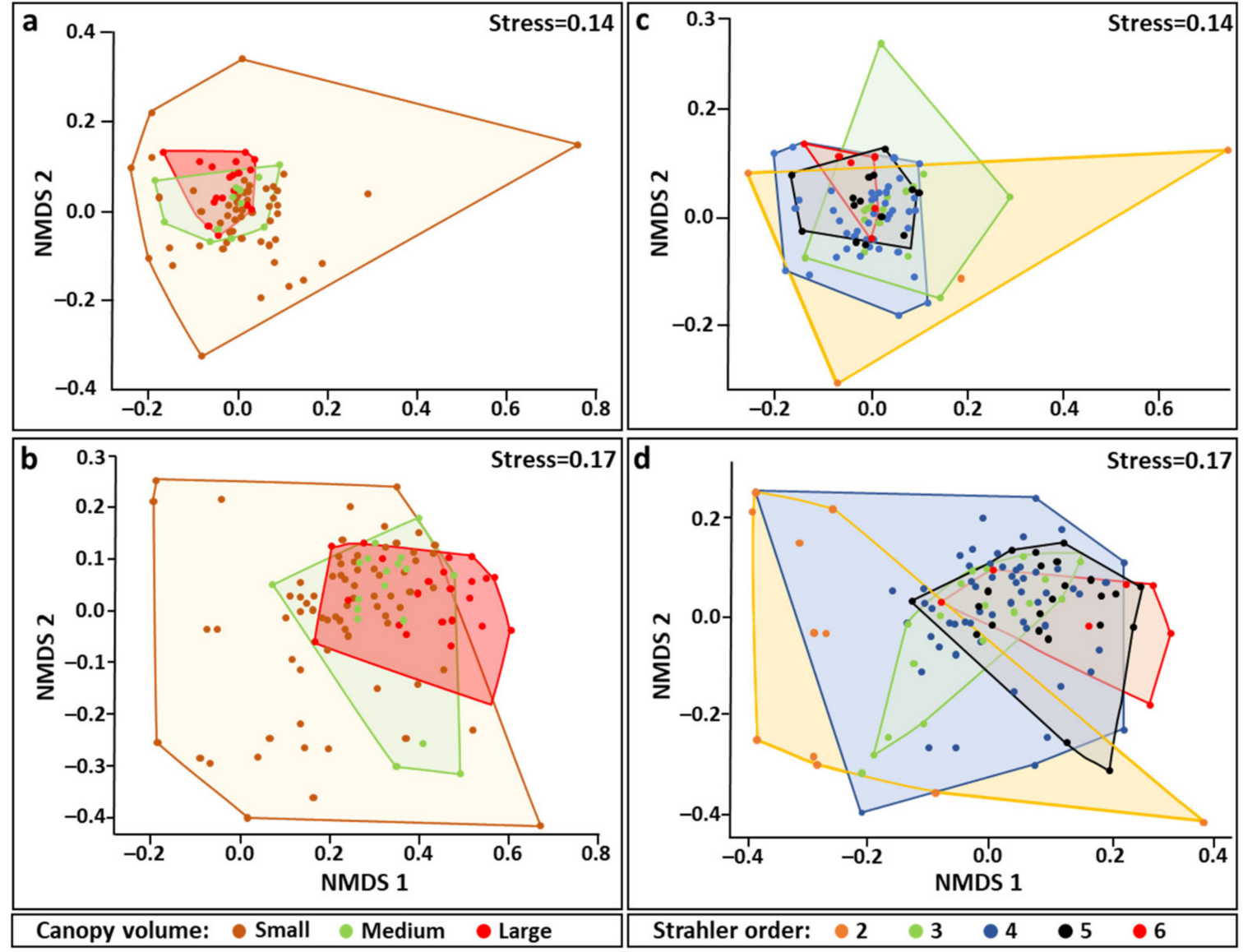

Figure 4. Nonmetric multidimensional scaling ordination plots for Bray-Curtis distance matrix of community dissimilarities based on 0.85 square transformation of $\mathrm{S}$. pistillata dwelling species abundance data. $(\mathbf{a}, \mathbf{b})$ communities grouped by canopy size (large, medium small) at day and night time, respectively; (c,d) communities grouped by canopy Strahler order numbers (2-6) at day and night, respectively. Each canopy community sample is represented by a colored point. 2D stress values are marked for each plot.

\subsection{Species Distribution in Canopy Compartments}

The most common crustaceans living between the canopy branches were the brachyurans Trapezia cymodoce and Trapezia digitalis. At night T. cymodoce was recorded in 105/114 S. pistillata canopies studied, with up to 5 large specimen/canopy, and up to 7 (2 large, 3 medium and 2 small) individuals per canopy. T. cymodoce and T. digitalis were sympatric, found to reside side by side in the same canopies, and only $2 / 55$ canopies with $T$. digitalis did not harbor T. cymodoce. The maximum number of both species residing in the same canopy was 9 (6 canopies). Although most $T$. digitalis specimen belong to the medium size class ( $77 \%$ day, $62 \%$ night), in most of the observations, they sympatrically shared the canopy with the large body size T. cymodoce. Colonies of canopy Strahler number 2 had only one small or medium body size T. cymodoce specimen/colony (Supplementary Table S1). In addition, the different body size populations showed different distribution patterns in the canopy compartments at day and night (Figure 5). During the day, both species commonly dwelled on the canopy bases with dominant numbers for the larger-sized individuals (width $>1 \mathrm{~cm})$. At night, small individuals $(0.02-0.1 \mathrm{~cm})$ were found primarily $(87 \%$ for T. cymodoce, and $100 \%$ for T. digitalis) in the canopy's upper compartment ('up'), usually above the first bifurcation section (Figure 5), while most medium size crabs $(0.11-1 \mathrm{~cm}$ ) were recorded at the 'middle' compartment ( $82 \%$ for T. cymodoce, and $83 \%$ for T. digitalis), and the large size crabs were found between the canopy 'base' to the 'middle' compartment (Figure 5). PERMANOVA results (Table 3) for both species revealed that the interaction 
'individual size' vs. 'time (day/night)' was significant $(p<0.002)$ for the assemblages along the canopy compartments. Pairwise posteriori comparisons for T. cymodoce indicated that the dispersal structures were significantly different between all three group sizes $(p<0.001)$; for T. digitalis, significant differences were found between small to medium and large animal sizes, but not between medium and large body size groups (Table 3, Figure 5).
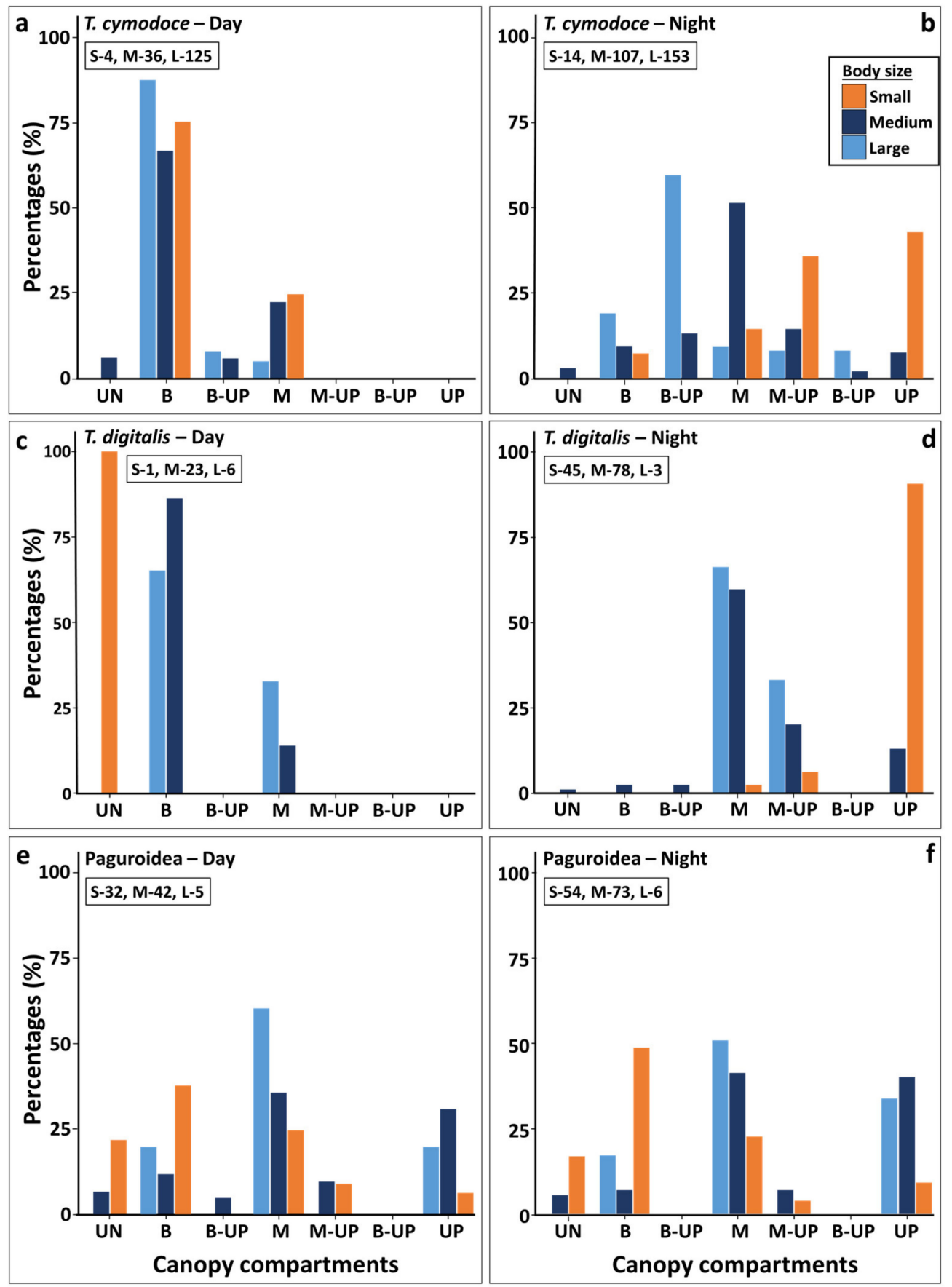

Figure 5. Proportion of three S. pistillata dwelling crustacean species according to their distribution between canopy compartments and their body-size groups during day and night censuses (left and right graphs, accordingly). (a,b) T. cymodoce; (c,d) T. digitalis; (e,f) Paguridae. Individual total observations by their size (L large, $\mathrm{M}$ medium, $\mathrm{S}$ small) are marked for each plot. Percentage was calculated according to the total abundance of each species size group for each day time census (UN) understory; (B) base; (M) middle; (B-UP) base, middle, and up; (M-UP) middle and up compartments. 
Table 3. Summary of two-way PERMANOVA testing for the effect of canopy dwelling species body size (small, medium, and large), daily time (day, night), and their canopy compartments occupation. Analyses were performed separately for each species based on Bray-Curtis dissimilarity and a 1.7 power transformation matrix of compartments distribution. Significant values are presented in bold $(p<0.05)$.

\begin{tabular}{|c|c|c|c|c|c|c|}
\hline \multicolumn{7}{|c|}{ Two-Way PERMANOVA } \\
\hline Source of variation & & $\mathrm{df}$ & MS & F.Model & $\mathrm{R} 2$ & $P$ \\
\hline \multirow[t]{5}{*}{ Trapezia cymodoce } & Size & 2 & 4.2705 & 15.309 & 0.09613 & 0.001 \\
\hline & Time & 1 & 13.3858 & 47.987 & 0.15066 & 0.001 \\
\hline & Size, Time & 2 & 1.3802 & 4.948 & 0.03107 & 0.001 \\
\hline & Residual & 230 & 0.2789 & & 0.72213 & \\
\hline & Total & 235 & & & 1 & \\
\hline \multirow[t]{5}{*}{ Trapezia digitalis } & Size & 2 & 3.1561 & 11.513 & 0.17034 & 0.001 \\
\hline & Time & 1 & 5.0316 & 18.354 & 0.13579 & 0.001 \\
\hline & Size, Time & 2 & 0.6566 & 2.395 & 0.03544 & 0.002 \\
\hline & Residual & 89 & 0.2741 & & 0.65843 & \\
\hline & Total & 94 & & & 1 & \\
\hline \multirow[t]{5}{*}{ Paguroidea } & Size & 2 & 0.82091 & 2.04778 & 0.04316 & 0.033 \\
\hline & Time & 1 & 0.23972 & 0.59799 & 0.0063 & 0.686 \\
\hline & Size, Time & 2 & 0.03857 & 0.09621 & 0.00203 & 1 \\
\hline & Residual & 90 & 0.40088 & & 0.94851 & \\
\hline & Total & 95 & & & 1 & \\
\hline \multicolumn{7}{|c|}{ Pairwise permutation MANOVA } \\
\hline & \multicolumn{3}{|c|}{ Species body size } & \multicolumn{3}{|c|}{ Time } \\
\hline & Small & Medi & Large & \multicolumn{2}{|c|}{ Day } & Night \\
\hline Trapezia cymodoce & $\mathrm{a}$ & $b$ & C & \multicolumn{2}{|c|}{ A } & B \\
\hline Trapezia digitalis & $\mathrm{a}$ & $\mathrm{b}$ & $\mathrm{bc}$ & \multicolumn{2}{|c|}{$\mathrm{A}$} & $\mathrm{B}$ \\
\hline Paguroidea & $\mathrm{a}$ & $\mathrm{b}$ & $\mathrm{ab}$ & \multicolumn{2}{|c|}{ A } & A \\
\hline
\end{tabular}

In contrast to the Trapezia species, the distribution of hermit crabs (Figure 5) did not significantly differ between day and night. Although small body-sized (shell diameter $<1 \mathrm{~cm}$ ) individuals were found with higher proportions $(62 \%)$ at the canopy lower compartments ('understory' to 'base'), the larger individuals (medium 3-1 $\mathrm{cm}$ and large $>3 \mathrm{~cm}$, shell diameter) were more prevalent at the 'middle' and 'up' compartments (85\%). Overall, the larger individuals were not prevalent in the canopy (11 out of total 212 day and night individuals) and significant differences were found only between the small to the medium group sizes $(p<0.023$; Table 3$)$.

Shifts in compartments' positions between day and night were further documented for other species. The crustacean Alpheus lottini, and the fish Paragobiodon echinocephalus, which were hardly documented during day surveys ( 1 and 7 colonies, respectively), were always associated with the canopy base (Shmuel, unpublished data), yet, during nighttime they were recorded in the canopy middle compartments ( 8 and 22 colonies, respectively). The radial shield of the brittle stars Ophiocoma and Ophiactis species were found during the day at the inner canopy compartments (base) and their arms folded or stretched throughout the inside spaces of all canopy compartments. During night hours, their arms extended outside the canopy volume, beyond the topmost compartment or on the ground away from the understory compartment. Similarly, specimen of the fish Sebastapistes cyanostigma were commonly found during the day inside the canopy, usually from the base to the middle canopy, while at night found foraging primarily from the topmost compartment towards the understory. In contrast, specimen of the fish Pseudochromis olivaceus were found swimming through all canopy compartments during the day hours and, at night, found at the base to middle compartments, never out of the canopy space (Figure 6).

While the sessile species $(n=11)$ were found in all canopy compartments, some $(n=4)$ predominantly dwelled in specific parts. For example, more than $50 \%$ of the boring bivalve 
Leiosolenus lessepsianus specimen were found at the bifurcation points of branches and the gall crabs were found at the branch tips. Specimen of the tube building annelid were found at all canopy compartments, nevertheless, specimen of genus Sabellastarte were never found projecting out of the canopy space unlike specimen of the genus Spirobranchus (Figure 6).

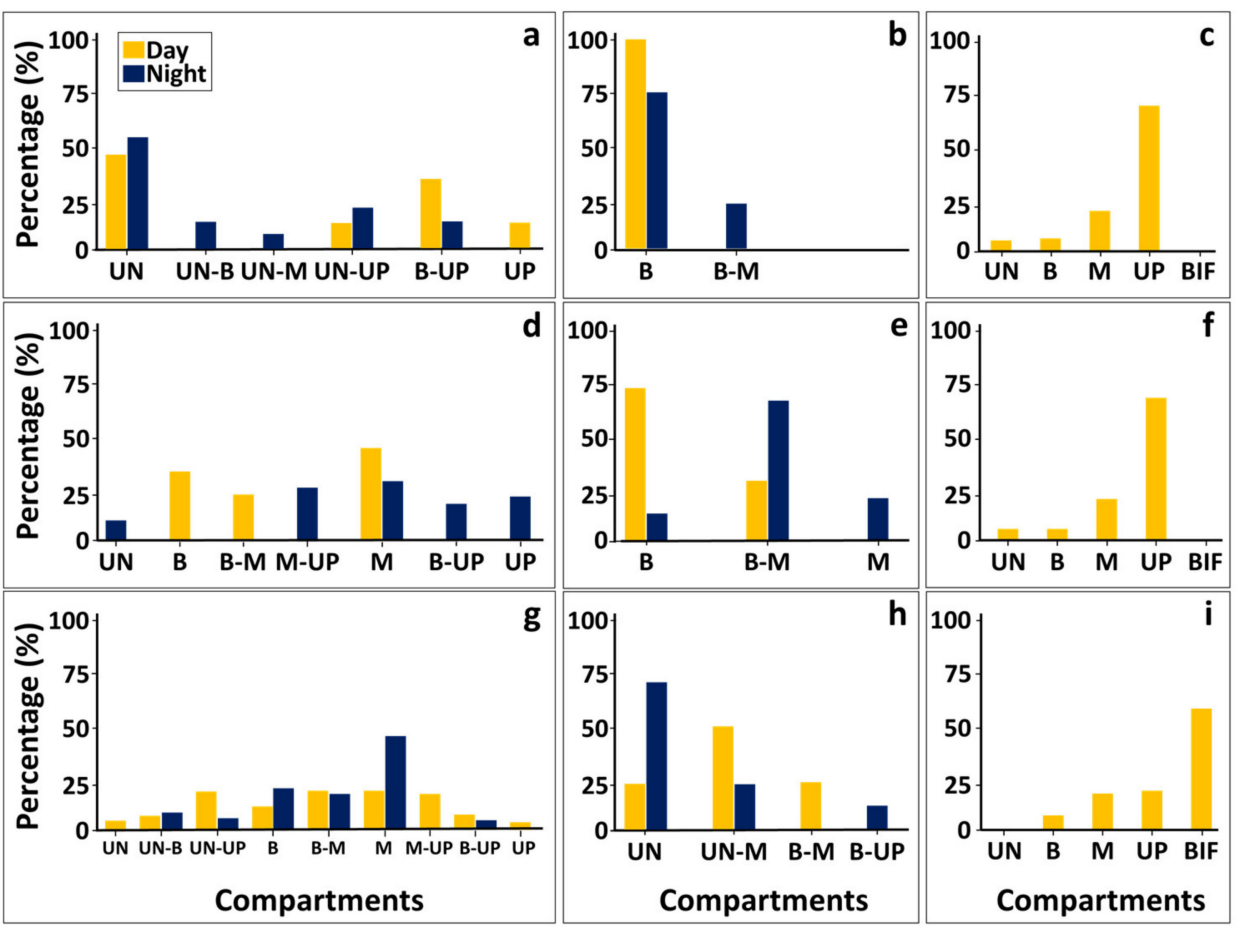

Figure 6. Proportion of Stylophora pistillata dwelling species according to their distribution between the canopy compartments during day and night censuses (mobile species), and for the sessile species (day surveys). (a) Ophiocoma sp.; (b) Alpheus lottini; (c) Spirobranchus sp.; (d) Sebastapistes cyanostigma; (e) Paragobidon echinocephalus; (f) Palaemonella rotumana; (g) Pseudochromis olivaceus; (h) Ophiactis sp.; (i) Leiosolenus lessepsianus. Percentage were calculated according to the total abundance of each species for each day time census (UN) understory, (B) base, (M) middle, (BIF) bifurcation nods; (UN-B) understory and base; (UN-M) understory, base, and middle; (UN-UP) understory, base, middle, and up; (B-M) base and middle; (B-UP) base, middle, and up; (M-UP) middle, and up compartments.

\section{Discussion}

Here we examined canopy-dwelling macro species in five major canopy compartmentations of the coral species S. pistillata from the Gulf of Eilat. We used, for the first time, the Strahler order number of branches as the key spatial differentiation factor. The fauna recorded included 11 sessile and 21 mobile species that dwell in the canopy spaces. Canopies with higher Strahler numbers had higher diversity and abundance of dwellers. Most importantly, coral-dwelling species showed compartmental preference and mobile species exhibited temporal variation in diversity and in compartment allocation between day and night, and between size distributions. This new approach provides us with a different strategy to analyze the complex coral canopy structural morphologies and landscape in relation to residing macro-biota within designed compartments.

The literature on biota residing within canopy spaces of branching corals has generally focused on the influence of two levels of attributes: the coral physical structure, such as coral species, coral height, volume, interbranch space, surface area, etc., and the coral's associated abiotic factors such as depth, flow regime, reginal scale, etc. [15,18,26-31,48,49]. In both cases, species assemblages and compositions were explicated by considering the whole canopy as a single space, without weighting the different niche types created within the canopy. As an example, small interbranch spaces, a biological feature that creates a 
suitable bed for juvenile crabs, may direct different space-dwelling outcomes to different canopy spaces [30].

Weighting the canopy's niche types in S. pistillata (an approach supported by employing the Strahler number ordering) allows an improved analysis and easy quantification of the coral canopy complexity under field conditions. It further resulted in the documentation of a climax dwelling assemblages as the coral reaches complexity of Strahler number 3 at day time, and 5-6 at night time. All the above are new documentations for novel approaches in the research of marine animal forests $[7,50,51]$. The employment of the Strahler ordering may further response to long-standing unresolved questions, such as how similar are the species richness and abundance of coral dwellers between different colonial sizes and between different coral species of the same size, all revealing the benefits of using this new analysis of coral canopy's complexity.

The results of the present study further elucidated fluctuations in day/night compartmental biodiversity and distributions as demographic dynamic elements, shaping the coral canopy's residency at the species level, and at the individual sizes within a species population. Distinct from former studies that revealed diurnal changes at higher spatial scales [52-56], the present study elucidated an important nocturnal play, a nighttime ecology, with less studied, not quantified spatial and temporal variations when compared with the daytime 'ecological theater' [57]. Our results further resemble results performed on arboreal canopies, revealing diel variations among and within species assemblages at canopy scales [58-60]. Studies have further revealed (reviewed in [57]) that a high proportion of animal species are nocturnal and that major comparisons between daytime and nighttime ecology remain largely unknown. The day/night field surveys of the present study provide the first evidence not only of an important nocturnalism but also of biodiverse diurnal/size niche partitions within the coral space, Thus, nighttime ecology, assisted by the corals canopy-complexity should not be underplayed. This novel aspect in the ecological features of megabenthic animal forests, features structurally and functionally similar with terrestrial forests, further disclosing increased niches/habitats complexities and biodiversity patterns [41,51,61-64].

The canopy Strahler associated animal distribution established for S. pistillata's residing biota, indicates fauna biodiversity and dispersal that are tightly associated with morphometric complexity, beyond the classical analyses that focus on the Stylophora's colony pattern formation rules $[4,10-12,20,65]$ and on the growth rules studied for other hermatypic corals (e.g., [66-69]). Other studies have referred the spatial complexity of Stylophora (and other branching coral species) as related to secreted isomones found in the water column [70] or to environmental conditions such as fluxes of nutrients in seawater [65,68], gravity [71], light intensity [72], and water flow [73]. In addition to all above approaches, the branch ordering hierarchy adds to the understanding of the functional properties of the coral canopies and is revealed here as a major component for evaluating special distributions and biodiversity of canopy-dwelling species in branching corals, allowing day/night shifts following other biological traits of residing organisms (like food foraging [74-76]) and group size niches within the spaces created by coral canopies.

Stylophora pistillata is a widely distributed Indo-Pacific branching coral species characterized by rapid growth rate and colonies exhibit an axially rod-like growth form where each branch consists of numerous minute polyps [19], altogether forming a complex 3D structures with a wide range of spaces. As such, S. pistillata becomes an ecologically important key species forming ecological niches for many reef residing species such as crabs (mainly Trapeziidae and Alpheidae), fish (especially Pomacentridae and Gobiidae), as well as a variety of cryptic organisms such as sponges, bivalves, polychaetes and others [19]. This species may resemble a typical case of the groups of organisms cumulatively known as 'animal forests' [7], a term that conceptualized the wide range of the 3D living structures governed by sessile animals. Like terrestrial trees, animal forests support diverse organisms that use their canopy structures, intra-spaces, and products [14,50,77-81]. Therefore, coral and tree habitats are expected to share similar dynamics with their associated species. 
Implementation of terrestrial ecological processes and methodologies, such as the effect of pure stand or plantation microhabitats on biodiversity [82-84], may accelerate and improve marine forest protection and management.

Although much similarity exists between branching coral architectures and tree structures, the 3D construction of coral colonies, in contrast to trees, is made up of tessellation of their structural modular units; the polyps [19] lack the hierarchical anatomy organization of the tree units (e.g., leaves, branches, trunk, and roots). Thus, small-scale specialisation processes of cryptic coral biota such as vertical stratification $[63,64]$ may easily be unnoticed. Hence, Strahler ordering is a simple way to quantify structural complexity of branching organisms, trees and corals alike, while ignoring the type of the unit and placing any type of branches within unique hierarchical orders, that are structurally and functionally distinct from each other (first order is the stip of the unit and the last order is the base). Moreover, this approach for analyzing the 3D structures of coral canopies provides a new and additional dimension to the matrices used, including approaches that analyze coral pattern formation $[68,72,85,86]$, and astogeny $[20,87]$ and approached that reveal nocturnal behaviors of canopy's dwellers, affecting ecosystem functions and processes [49]. Comprehension of the dynamics of this ordering will augment the understanding of the structural rules coral colonies provide to support and sustain associated biota.

Supplementary Materials: The following supporting information can be downloaded at https: / / www.mdpi.com/article/10.3390/jmse10010121/s1. Table S1: Day and night survey results of Stylophoara pistillata attributes and dwelling species. Table S2: Paired permutation $t$-test summary results between day and night of Stylophora pistillata $(n=114)$ canopy dwelling species biodiversity indices. Table S3: Summary results of linear regression of coral volume and Strhaler order vs. richness and abundance at day and night. Table S4: Summary results of Permutation one-way ANOVA and Pairwise permutation test of canopy Strahler number as categorial factor (1-6) vs. richness and abundance.

Author Contributions: Conceptualization, Y.S. and B.R.; survey and methodology, Y.S.; software, Y.S.; validation, Y.S. and B.R.; formal analysis, Y.S.; investigation, Y.S.; resources, B.R.; data curation, Y.S.; writing-original draft preparation, Y.S. and B.R.; writing-review and editing, Y.S., B.R. and Y.Z.; visualization, Y.S.; supervision, B.R. and Y.Z.; project administration, Y.S. and B.R.; funding acquisition, B.R. All authors have read and agreed to the published version of the manuscript.

Funding: This research was funded by the North American Friends of IOLR (NAF/IOLR), and the Barrett Foundation.

Institutional Review Board Statement: The study was conducted according to national guidelines and permits no 42516 by the Israeli Nature.

Informed Consent Statement: Not applicable.

Data Availability Statement: Raw data is appended in the Supplementary Materials.

Acknowledgments: We wish to thank to G. Paz for assisting with visualization, to S. Preiss-Bloom and B. Poodiack for editorial assistance, and to the staff of the Interuniversity Institute for Marine Science in Eilat for their help and support.

Conflicts of Interest: The authors declare no conflict of interest.

\section{References}

1. Connell, J.H. Diversity in tropical rain forests and coral reefs. Science 1978, 199, 1302-1310. [CrossRef]

2. Barlow, J.; França, F.; Gardner, T.A.; Hicks, C.C.; Lennox, G.D.; Berenguer, E.; Castello, L.; Economo, E.P.; Ferreira, J.; Guénard, B.; et al. The future of hyperdiverse tropical ecosystems. Nature 2018, 559, 517-526. [CrossRef] [PubMed]

3. Reaka-Kudla, L.M. The Global Biodiversity of Coral Reefs: A Comparison with Rain Forests. In Biodiversity II: Understanding and Protecting Our Biological Resources; Reaka-Kudla, L.M., Wilson, D.E., Wilson, E.O., Eds.; Joseph Henry Press: Washington, DC, USA, 1997; pp. 83-108.

4. Epstein, N.; Bak, R.P.M.; Rinkevich, B. Applying forest restoration principles to coral reef rehabilitation. Aquat. Conserv. Mar. Freshw. Ecosyst. 2003, 13, 387-395. [CrossRef] 
5. McElhinny, C.; Gibbons, P.; Brack, C.; Bauhus, J. Fauna-habitat relaionships: A basis for identifying key stand structural attributes in temperate Australian eucalypt forests and woodlands. Pacific Conserv. Biol. 2006, 12, 89-110. [CrossRef]

6. Hiroaki, T.I.; Tanabe, S.-I.; Tsutom, H. Exploring the relationships among canopy structure, stand productivity, and biodiversity of temperate forest ecosystems. For. Sci. 2004, 50, 342-355. [CrossRef]

7. Rossi, S.; Bramanti, L.; Gori, A.; Orejas, C. Marine Animal Forests: The Ecology of Benthic Biodiversity Hotspots; Springer: Cham, Switzerland, 2017; pp. 1-28.

8. Southwood, T.R.E. Habitat as the template for ecological strategies? J. Anim. Ecol. 1977, 46, 336-365. [CrossRef]

9. Wilson, S.K.; Graham, N.A.J.; Polunin, N.V.C. Appraisal of visual assessments of habitat complexity and benthic composition on coral reefs. Mar. Biol. 2007, 151, 1069-1076. [CrossRef]

10. Shaish, L.; Abelson, A.; Rinkevich, B. Branch to colony trajectory in a modular organism: Pattern formation in the indo-pacific coral Stylophora pistillata. Dev. Dyn. 2006, 235, 2111-2121. [CrossRef]

11. Shaish, L.; Abelson, A.; Rinkevich, B. How plastic can phenotypic plasticity be ? The branching coral Stylophora pistillata as a Model System. PLoS ONE 2007, 2, e644. [CrossRef]

12. Guerrini, G.; Shefy, D.; Shashar, N.; Shafir, S.; Rinkevich, B. Morphometric and allometric rules of polyp's landscape in regular and chimeric coral colonies of the branching species Stylophora pistillata. Dev. Dyn. 2021, 250, 652-668. [CrossRef]

13. Parker, G.G. Structure and Microclimate of Forest Canopies. In Forest Canopies; Nadkarni, N.M., Ed.; Academic Press: San Diego, CA, USA, 1995; pp. 73-98.

14. Stella, J.S.; Pratchett, M.S.; Hutchings, P.A.; Geoffrey, J.P. Coral-associated invertebrates: Diversity, ecological importance and vulnerability to disturbance. In Oceanography and Marine Biology: An Annual Review; CRC Press: Boca Raton, FL, USA, 2011; Volume 49, pp. 43-104.

15. Stella, J.S.; Jones, G.P.; Pratchett, M.S. Variation in the structure of epifaunal invertebrate assemblages among coral hosts. Coral Reefs 2010, 29, 957-973. [CrossRef]

16. Graham, N.A.J.; Nash, K.L. The importance of structural complexity in coral reef ecosystems. Coral Reefs 2013, 32, 315-326. [CrossRef]

17. Britayev, T.A.; Mikheev, V.N. Clumped spatial distribution of scleractinian corals influences the structure of their symbiotic associations. Dokl. Biol. Sci. 2013, 448, 45-48. [CrossRef] [PubMed]

18. Counsell, C.W.W.; Donahue, M.J.; Edwards, K.F.; Franklin, E.C.; Hixon, M.A. Variation in coral-associated cryptofaunal communities across spatial scales and environmental gradients. Coral Reefs 2018, 37, 827-840. [CrossRef]

19. Rinkevich, B. the Branching Coral Stylophora Pistillata: Contribution of Genetics in Shaping Colony Landscape. Isr. J. Zool. 2002, 48, 71-82. [CrossRef]

20. Shaish, L.; Rinkevich, B. Critical Evaluation of Branch Polarity and Apical Dominance as Dictators of Colony Astogeny in a Branching Coral. PLoS ONE 2009, 4, e4095. [CrossRef]

21. Glynn, P.W. Increased survivorship on corals harbouring crustacean symbionts. Mar. Biol. Lett. 1983, 4, $105-111$.

22. Tsuchiya, M.; Taira, A. Population structure of six sympatric species of Trapezia associated with the hermatypic coral Pociliopora damicornis with a hypothesis of mechanisms promoting their coexistence. J. Jpn. Coral Reef Soc. 1999, 1, 9-17. [CrossRef]

23. Sin, T. Distribution and host specialization in Tetralia crabs (Crustacea: Brachyura) symbiotic with corals in the Great Barrier Reef, Australia. Bull. Mar. Sci. 1999, 65, 839-850.

24. Austin, A.D.; Austin, S.A.; Sale, P.F. Community structure of the fauna associated with the coral Pocillopora damicornis (L.) on the Great Barrier Reef. Aust. J. Mar. Freshw. Res. 1980, 31, 163-174. [CrossRef]

25. Huber, M.; Coles, S. Resource utilization and competition among the five Hawaiian species of Trapezia (Crustacea, Brachyura). Mar. Ecol. Prog. Ser. 1986, 30, 21-31. [CrossRef]

26. Carvalho, S.; Cúrdia, J.; Pereira, F.; Guerra-garcía, J.M.; Santos, M.N.; Cunha, M.R. Biodiversity patterns of epifaunal assemblages associated with the gorgonians Eunicella gazella and Leptogorgia lusitanica in response to host, space and time. J. Sea Res. 2014, 85, 37-47. [CrossRef]

27. Cúrdia, J.; Carvalho, S.; Pereira, F.; Guerra-García, J.M.; Santos, M.N.; Cunha, M.R. Diversity and abundance of invertebrate epifaunal assemblages associated with gorgonians are driven by colony attributes. Coral Reefs 2015, 34, 611-624. [CrossRef]

28. Britayev, T.A.; Spiridonov, V.A.; Deart, Y.V.; El-Sherbiny, M. Biodiversity of the community associated with Pocillopora verrucosa (Scleractinia: Pocilloporidae) in the Red Sea. Mar. Biodivers. 2017, 47, 1093-1109. [CrossRef]

29. Edwards, A.; Emberton, H. Crustacea associated with the scleractinian coral, Styolophora pistillata (Esper), in the Sudanese Red sea. J. Exp. Mar. Bio. Ecol. 1980, 42, 225-240. [CrossRef]

30. Vytopil, E.; Willis, B. Epifaunal community structure in Acropora spp. (Scleractinia) on the Great Barrier Reef: Implications of coral morphology and habitat complexity. Coral Reefs 2001, 20, 281-288. [CrossRef]

31. Pisapia, C.; Stella, J.; Silbiger, N.J.; Carpenter, R. Epifaunal invertebrate assemblages associated with branching Pocilloporids in Moorea, French Polynesia. PeerJ 2020, 8, e9364. [CrossRef]

32. Sin, T.M.; Lee, A.C. Host specialisation in trapeziid crabs: Consequences for rarity at local scales. In Proceedings of the 9th International Coral Reef Symposium, Bali, Indonesia, 23-27 October 2000; pp. 23-27.

33. Strahler, A.N. Quantitative analysis of watershed geomorphology. Trans. Am. Geophys. Union 1957, 38, 913-920. [CrossRef]

34. Leopold, L.B. Trees and streams: The efficiency of branching patterns. J. Theor. Biol. 1971, 31, 339-354. [CrossRef] 
35. Oohata, S.I.; Shidei, T. Studies on the branching structure of trees: I. Bifurcation ratio of trees in Horton's. Jpn. J. Ecol. 1971, 21, $7-14$.

36. Whitney, G.G. The bifurcation ratio as an indicator of adaptive strategy in woody plant species. Bull. Torrey Bot. Club 1976, 103, 67-72. [CrossRef]

37. McMahon, T.A.; Kronauer, R.E. Tree structures: Deducing the principle of mechanical design. J. Theor. Biol. 1976, 59, 443-466. [CrossRef]

38. Cheetham, A.H.; Hayek, L.A.C.; Thomsen, E. Branching structure in arborescent animals: Models of relative growth. J. Theor. Biol. 1980, 85, 335-369. [CrossRef]

39. Abraham, E.R. The fractal branching of an arborescent sponge. Mar. Biol. 2001, 138, 503-510. [CrossRef]

40. MacArthur, R.H.; MacArthur, J.W. On bird species diversity. Ecology 1961, 42, 594-598. [CrossRef]

41. Crowder, L.B.; Cooper, W.E. habitat structural complexity and the interaction between bluegills and their prey. Ecology 1982, 63, 1802-1813. [CrossRef]

42. Oksanen, J.; Blanchet, F.G.; Friendly, M.; Kindt, R.; Legendre, P.; McGlinn, D.; Minchin, P.R.; O’Hara, R.B.; Simpson, G.L.; Solymos, P.; et al. Vegan: Ecological diversity. R Package Version 2.4-4. 2017. Available online: https://cran.r-project.org/web/packages/ vegan/index.html (accessed on 12 March 2021).

43. Hervé, M. RVAideMemoire: Testing and plot. R Package Version 0.9-73. 2019. Available online: https:/ CRAN.R-project.org/ package=RVAideMemoire (accessed on 12 March 2021).

44. Weiss, N.A. wPerm. Permutation Tests. R Package Version 1.0.1. 2015. Available online: https://CRAN.R-project (accessed on 12 March 2021).

45. Mangiafico, S. 'rcompanion: Functions to support extension education program evaluation. R Package Version 1.0.1. 2021. Available online: https:/ /CRAN.R-project.org/package=rcompanion (accessed on 12 March 2021).

46. Wheeler, R.E.; Torchiano, M. ImPerm: Permutation tests for linear models. R Package Version 2.1.0. 2016. Available online: https: / /CRAN.R-project.org/package=lmPerm (accessed on 12 March 2021).

47. Goslee, S.C.; Urban, D.L. The ecodist package for dissimilarity-based analysis of ecological data. J.Stat.Softw. 2007, 22, 1-19. [CrossRef]

48. Patton, W.K. Distribution and ecology of animals associated with branching corals (Acropora spp.) from the Great Barrier Reef, Australia. Bull. Mar. Sci. 1994, 55, 193-211.

49. Nogueira, M.M.; Neves, E.; Johnsson, R. Effects of habitat structure on the epifaunal community in Mussismilia corals: Does coral morphology influence the richness and abundance of associated crustacean fauna ? Helgol. Mar. Res. 2015, 69, 221-229. [CrossRef]

50. Sánchez, J.A. Diversity and Evolution of Octocoral Animal Forests at Both Sides of Tropical America. In Marine Animal Forests; Rossi, S., Bramanti, L., Gori, A., Orejas, C., Eds.; Springer: Cham, Switzerland, 2017; pp. 111-144.

51. Rice, J.; Smith, A.D.M. Ecosystem-Based Management: Opportunities and Challenges for Application in the Ocean Forest. In Marine Animal Forests; Rossi, S., Bramanti, L., Gori, A., Orejas, C., Eds.; Springer: Cham, Switzerland, 2017; pp. $965-988$.

52. Unsworth, R.K.F.; Wylie, E.; Smith, D.J.; Bell, J.J. Diel trophic structuring of seagrass bed fish assemblages in the Wakatobi Marine National Park, Indonesia. Estuar. Coast. Shelf Sci. 2007, 72, 81-88. [CrossRef]

53. Ebeling, A.W.; Bray, R.N. Day versus night activity of reef fishes in a kelp forest off Santa Barbara, California. Fish. Bull. 1976, 74, 703-717.

54. Forward, R.B. Diel vertical migration: Zooplankton photobiology and behaviour. Oceanogr. Mar. Biol. Ann. Rev. 1988, 26, 361-393.

55. Azzurro, E.; Pais, A.; Consoli, P.; Andaloro, F. Evaluating day-night changes in shallow mediterranean rocky reef fish assemblages by visual census. Mar. Biol. 2007, 151, 2245-2253. [CrossRef]

56. Young, M.A.L.; Bellwood, D.R. Diel patterns in sea urchin activity and predation on sea urchins on the Great Barrier Reef. Coral Reefs 2011, 30, 729-736. [CrossRef]

57. Gaston, K.J. Nighttime ecology: The "nocturnal problem" revisited. Am. Nat. 2019, 193, 481-502. [CrossRef]

58. Costa, J.T., III; Crossley, D.A. Diel patterns of canopy arthropods associated with three tree species. Environ. Entomol. 1991, 20, 1542-1548. [CrossRef]

59. Basset, Y.; Springate, N.D. Diel activity of arboreal arthropods associated with a rainforest tree. J. Nat. Hist. 1992, 26, 947-952. [CrossRef]

60. Lopes, J.R.S.; Nault, L.R.; Phelan, P.L. Periodicity of diel activity of Graminella nigrifrons (Homoptera: Cicadellidae) and Implications for Leafliopper Dispersal. Ann. Entomol. Soc. Am. 1995, 88, 227-233. [CrossRef]

61. Orth, R.J.; Heck, K.L.; van Montfrans, J. Faunal communities in seagrass beds: A review of the influence of plant structure and prey characteristics on predator-prey relationships. Estuaries 1984, 7, 339-350. [CrossRef]

62. Stork, N.E.; Blackburn, T.M. Abundance, body size and biomass of arthropods in tropical forest. Oikos 1993, 67, 483-489. [CrossRef]

63. Basset, Y.; Hammond, P.M.; Barrios, H.; Holloway, J.D.; Miller, S.E. Vertical Stratification of Arthropod Assemblages. In Arthropods of Tropical Forests; Basset, Y., Novotny, V., Miller, S.E., Kitching, R.L., Eds.; Cambridge University Press: Cambridge, UK, 2003; pp 17-27.

64. Aikens, K.R.; Buddle, C.M. Small-scale heterogeneity in temperate forest canopy arthropods: Stratification of spider and beetle assemblages. Can. Entomol. 2012, 144, 526-537. [CrossRef] 
65. Kücken, M.; Rinkevich, B.; Shaish, L.; Deutsch, A. Nutritional resources as positional information for morphogenesis in the stony coral Stylophora pistillata. J. Theor. Biol. 2011, 275, 70-77. [CrossRef]

66. Dustan, P. Growth and form in the reef-building coral Montastrea annularis. Mar. Biol. 1975, 33, 101-107. [CrossRef]

67. Ayre, D.J.; Willis, B.L. Population structure in the coral Pavona cactus: Clonal genotypes show little phenotypic plasticity. Mar. Biol. 1988, 99, 495-505. [CrossRef]

68. Kaandorp, J.A.; Sloot, P.M.A.; Merks, R.M.H.; Bak, R.P.M.; Vermeij, M.J.A.; Maier, C. Morphogenesis of the branching reef coral Madracis mirabilis. Proc. R. Soc. B Biol. Sci. 2005, 272, 127-133. [CrossRef]

69. Lartaud, F.; Galli, G.; Raza, A.; Priori, C.; Benedetti, M.C.; Cau, A.; Santangelo, G.; Iannelli, M.; Solidoro, C.; Bramanti, L. Growth Patterns in Long-Lived Coral Species Marine. In Marine Animal Forests; Rossi, S., Bramanti, L., Gori, A., Orejas, C., Eds.; Springer: Cham, Switzerland, 2017; pp. 595-626.

70. Rinkevich, B.; Loya, Y. Coral isomone: A proposed chemical signal controlling intraclonal growth patterns in a branching coral. Bull. Mar. Sci. 1985, 36, 319-324.

71. Meroz, E.; Brickner, I.; Loya, Y.; Peretzman-Shemer, A.; Ilan, M. The effect of gravity on coral morphology. Proc. R. Soc. B: Biol. Sci. 2002, 269, 717-720. [CrossRef]

72. Muko, S.; Kawasaki, K.; Sakai, K.; Takasu, F.; Shigesada, N. Morphological plasticity in the coral Porites sillimaniani and its adaptive significance. Bull. Mar. Sci. 2000, 66, 225-239.

73. Shwartsberg, M.; Kizner, Z.; Dubinsky, Z.; Bachar, A. Morphological growth response of Stylophora Pistillata TO in-situ manipulations of light intensity and water flow regime. Isr. J. Ecol. Evol. 2012, 58, 69-85. [CrossRef]

74. D'Onghia, G.; Maiorano, P.; Carlucci, R.; Capezzuto, F.; Carluccio, A.; Tursi, A.; Sion, L. Comparing Deep-Sea fish fauna between coral and non-coral "Megahabitats" in the Santa Maria di Leuca cold-Water coral province (Mediterranean Sea). PLoS ONE 2012, 7, e44509. [CrossRef]

75. D’Onghia, G.; Maiorano, P.; Sion, L.; Giove, A.; Capezzuto, F.; Carlucci, R.; Tursi, A. Effects of deep-water coral banks on the abundance and size structure of the megafauna in the Mediterranean Sea. Deep Sea Res. Part II Top. Stud. Oceanogr. 2010, 57, 397-411. [CrossRef]

76. Papastamatiou, Y.P.; Meyer, C.G.; Kosaki, R.K.; Wallsgrove, N.J.; Popp, B.N. Movements and foraging of predators associated with mesophotic coral reefs and their potential for linking ecological habitats. Mar. Ecol. Prog. Ser. 2015, 521, 155-170. [CrossRef]

77. Rinkevich, B.; Wolodarsky, Z.; Loya, Y. Coral-crab association: A compact domain of a multilevel trophic system. Hydrobiologia 1991, 216-217, 279-284. [CrossRef]

78. Idjadi, J.A.; Edmunds, P.J. Scleractinian corals as facilitators for other invertebrates on a Caribbean reef. Mar. Ecol. Prog. Ser. 2006, 319, 117-127. [CrossRef]

79. Wilson, S.K.; Burgess, S.C.; Cheal, A.J.; Emslie, M.; Fisher, R.; Miller, I.; Polunin, N.V.C.; Sweatman, H.P. Habitat utilization by coral reef fish: Implications for specialists vs. generalists in a changing environment. J. Anim. Ecol. 2008, 77, 220-228. [CrossRef]

80. López-Pérez, A.; Granja-Fernández, R.; Benítez-Villalobos, F.; Jiménez-Antonio, O. Pocillopora damicornis-associated echinoderm fauna: Richness and community structure across the southern Mexican Pacific. Mar. Biodivers. 2017, 47, 481-490. [CrossRef]

81. Maldonado, M.; Aguilar, R.; Bannister, R.J.; Bell, J.J.; Conway, K.W.; Dayton, P.K.; Díaz, C.; Gutt, J.; Kelly, M.; Kenchington, E.L.R.; et al. Sponge Grounds as Key Marine Habitats: A Synthetic Review of Types, Structure, Functional Roles, and Conservation Concerns. In Marine Animal Forests; Rossi, S., Bramanti, L., Gori, A., Orejas, C., Eds.; Springer: Cham, Switzerland, 2017; pp. 145-184.

82. Brockerhoff, E.G.; Jactel, H.; Parrotta, J.A.; Quine, C.P.; Sayer, J. Plantation forests and biodiversity: Oxymoron or opportunity? Biodivers. Conserv. 2008, 17, 925-951. [CrossRef]

83. Bremer, L.L.; Farley, K.A. Does plantation forestry restore biodiversity or create green deserts? A synthesis of the effects of land-use transitions on plant species richness. Biodivers. Conserv. 2010, 19, 3893-3915. [CrossRef]

84. Heinrichs, S.; Ammer, C.; Mund, M.; Boch, S.; Budde, S.; Fischer, M.; Müller, J.; Schöning, I.; Schulze, E.D.; Schmidt, W.; et al. Landscape-scale mixtures of tree species are more effective than stand-scale mixtures for biodiversity of vascular plants, bryophytes and lichens. Forests 2019, 10, 73. [CrossRef]

85. Martin-Garin, B.; Lathuilière, B.; Verrecchia, E.; Geister, J. Use of fractal dimensions to quantify coral shape. Coral Reefs 2007, 26, 541-550. [CrossRef]

86. Kim, Y.; Sinclair, R.; Chindapol, N.; Kaandorp, J.A.; de Schutter, E. Geometric theory predicts bifurcations in minimal wiring cost trees in biology are flat. PLoS Comput. Biol. 2012, 8, e1002474. [CrossRef] [PubMed]

87. Lee, D.J.; Noble, J.P.A. Colony development and formation in halysitid corals. Lethaia 1990, 23, 179-193. [CrossRef] 